of double-star astronomy in all its varied aspects; throughout his active career he pursued it with single-minded detachment, using to the full the advantages provided by the great 36 -in. refractor and the excellent conditions for observation on the summit of Mount Hamilton.

Aitken was appointed associate director of the Lick Observatory in 1923 and director in 1930 ; he retired in 1935 with the title of director emeritus. After his retirement he continued to take a keen interest in astronomy. He was in great demand as a lecturer and was very active in the affairs of the Astronomical Society of the Pacific; at the time of his death he was chairman of its Board of Directors. He was elected an associate of the Royal Astronomical Society in 1913; he was awarded the Catherine Bruce Gold Medal of the Astronomical Society of the Pacific in 1926 and the Gold Medal of the Royal Astronomical Society in 1932. He married in 1888 Jessie, daughter of Captain W. R. Thomas, and there were three sons and a daughter of the marriage.

H. SPENCER JONES

\section{Prof. C. K. Tinkler}

THE death on October 25 of Prof. C. K. Tinkler, formerly professor of chemistry in King's College of Household and Social Science, University of London, will be felt as a loss in many circles, particularly in the world of women's education-a world in which he ranked as a pioneer.

Prof. Tinkler was born in 1881 and received his early education at Caterham School. It was here that he first met V. H. Mottram, who on his appointment in 1920 as professor of physiology in Ting's College became his colleague and close associate. Tinkler graduated from the University College of North Wales, Bangor, and afterwards went to the University of Edinburgh to work under Prof. J. J. Dobbie. In 1904 he became a lecturer in the University of Birmingham, and during the following eleven years worked intensively both in teaching and research. He published many papers on alkaloids of the berberine type and cognate compounds, made a study of fuels, and in collaboration with a fellow lecturer published a book much valued in the petroleum industry, "The Chemistry of Petroleum", by Tinkler and Challenger.

In 1915 he was appointed a reader in the University of London and head of the Chemistry Department of King's College of Household and Social Science, then the Home Science Department of King's College for Women. It was to the work and development of this College that he devoted the remaining thirtytwo years of his professional career until his retirement in 1947 .

To understand fully the main achievements of Prof. Tinkler's life it is necessary to look back at the history of the College with which he was so closely identified. At the time of his appointment, the College was in its infancy. Only seven years pre. viously, in 1908, a course dealing with the scientific and social aspects of the household and institution had been run for the first time in a department of King's College for Women, a branch of King's College, Strand. In those days the idea that there could be any connexion between pure science and the mundane affairs of the kitchen and laundry was revolutionary, and still more revolutionary the idea that a liberal academic education for women could be based on subjects within their own sphere. Never- theless, a few great men of vision, Sir John Atkins, Sir Cooper Perry, Sir Herbert Jackson and Prof. A. Smithells, were convinced of the scope and necessity for this type of education for women; they devised and initiated the course, and collected by private enterprise sufficient money to acquire a site on Campden Hill, Kensington, and to begin building a college. If any justification of their faith be required, it is to be found in the universal acceptance to-day of their ideas and in the progress and expansion that have taken place in every aspect of the field they sought to cover : for example, in the science of foods, detergents, house-heating and ventilation, and even in the study of the social and economic relationship of the home to the community and the nation.

It was by a stroke of good fortune that Prof. Tinkler became a member of the small staff in 1915, for he was imbued by the same ideas, and threw himself whole-heartedly into the task of developing. the course and establishing the College and its work. His arrival took place at the opportune moment when the first instalment of the building, including the laboratories, was erected but not yet equipped. Here then was a situation calling for those qualities. with which Prof. Tinkler was well endowed-organizing ability, initiative and enthusiasm born of his ever-increasing and infectious faith in the whole: project.

Success came with the years : in 1920 a professorship was conferred upon him by the University of London, in 1921 the course was recognized by the University by the granting of the degree of B.Sc. (Household and Social Science), and in 1928 the College was recognized as an independent school of the University and given its present title. In the development, Prof. Tinkler was the leading spirit. His personality, combined with wisdom and knowledge, rendered him an invaluable committee member, an able representative of the College in the outside world, and the man to whom people instinctively turned for guidance in all matters, whether academic, practical, or administrative. Within his own depart. ment he applied himself from 1915 onwards to the task of devising a suitable course in chemistry to dovetail with the other subjects in the curriculum. In collaboration with Miss Helen Masters he created a course in applied chemistry unique in its scope and to the present day regarded as a model in home science departments throughout the world. The results of original work were embodied in this course from time to time. The practical work and some of the better established aspects of theory were published in two volumes: "Applied Chemistry", by Tinkler and Masters.

As a teacher, Prof. Tinkler excelled. He possessed a great store of knowledge of a wide range of practical matters and had a remarkable gift of clear exposition and a rare capacity for bridging the gap between the academic and practical aspects of his subject.

Agnes JaCkMaN

THE death is announced of Mr. J. E. Southeombe, a director of Germ Lubricants, Ltd., at the age of sixty-six. He graduated at the University of Liverpool in 1907, and after a short period of teaching in Ireland returned to Liverpool to do chemical research. He collaborated with the late Henry M. Wells in an investigation of the properties of 'fatty oils', and their use as compounding agents with mineral oils for lubrication; and afterwards specialized on 'boundary phase' lubrication problems. 